\title{
MUSEUS: EXPERIÊNCIA VERSUS NÚMEROS
}

Ivo Mesquita'

\section{RESUMO}

Texto apresentado durante o Workshop Modernismos: conceitos - contextos - circulação, organizado pela Academia Transregional do Deutsches Forum für Kunstgeschichte in Paris, o Instituto Goethe em São Paulo, a UNIFESP e o MAC USP, realizado na Vila Itororó, em São Paulo, no dia 23 de Julho de 2016. Pretendia trazer ao debate daquele encontro, uma perspectiva da corrente instrumentalização dos discursos sobre a arte e a produção artística, assim como lançar algumas provocações sobre as regras de mercado que parecem determinar não apenas o papel e o valor dos museus, mas ordenar e controlar o trabalho profissional do historiador da arte e de outros profissionais especializados, a mais valia explorada por esta nova economia dos museus sob a globalização.

\section{PALAVRAS-CHAVE}

economia dos museus; globalização; arte; produção artística

\section{MUSEUMS: EXPERIENCE VERSUS NUMBERS}

\section{ABSTRACT}

This text was originally presented during the Workshop Modernisms: Concepts - Contexts - Circulation, organized by the Transregional Academy of the Deutsches Forum für Kunstgeschichte in Paris, the Goethe Institut in São Paulo, the Federal University of São Paulo (UNIFESP), and the Museum of Contemporary Art of the University of São Paulo (MAC USP), at Vila Itororó, São Paulo, on July 23rd, 2016. For this occasion, my intention was to discuss the current instrumentalization of the discourses about art and artistic production, as well as to question the rules of the market, which seem to determine the role and value of museus. In addition to this, it seems to put into order and to control the professional work of the art historian and other experts, as the plus-value exploited in this new economy of museums in the globalization era.

\section{KEYWORDS}

museum economy; globalization; art; artistic production

\footnotetext{
' Ivo Mesquita é pesquisador e curador independente; vive e trabalha em São Paulo. Foi curador-chefe e diretor artístico da Pinacoteca do Estado de São Paulo (2006-20I5); Professor Visitante do Center for Curatorial Studies, Bard College, Nova York; Diretor Artístico da 28a. Bienal de São Paulo (2008) e do Museu de Arte Moderna de São Paulo (2000-2002). Tem colaborado com instituições culturais no Brasil e no exterior.
} 
Se há algum acontecimento que podemos dizer imprevisto na história dos museus foi o boom da arte contemporânea, como ela se converteu no centro do espetáculo da arte e da poderosa economia das exposições, com feiras e mostras internacionais periódicas ou circulantes, destronando os blockbusters de mestres clássicos ou do modernismo, os quais ela também vem superando em preços e valorização. Era algo praticamente inconcebível para a minha geração, formada entre os anos 1970-80. Ainda que o debate fosse sobre Duchamp, Broodthaers, Beuys, Naumann, arte conceitual e situacionistas, não havia um circuito para a produção de artistas emergentes, particularmente no Brasil. Eles tinham não apenas que fazer, mas também criar as condições de exposição dos seus trabalhos (artists running centers), de inserção deles num circuito cultural alternativo, bastante precário ou inexistente. Demandava generosidade, idealismo, muito investimento libidinal, quando comparamos com a cena atual, totalmente profissionalizada, com relações de produção organizadas, uma economia desigual, mas efetiva, e, sobretudo, institucionalizada.

Por certo que havia algo em processo com museus pioneiros como o Stedelijk, em Amsterdã, o Moderna Museet, em Estocolmo, a Kunsthalle, de Berna, o Walker Art Center, em Minneapolis, e por que não o MAC USP, entre poucos outros, que tinham assumidamente um compromisso com a promoção da arte contemporânea mais avançada, experimental como se dizia na época, conferindo-lhe alguma visibilidade institucional. Mas foi depois da abertura do Beaubourg, em Paris, 1976, que este fenômeno parece ter se consolidado, ampliado sua escala e levado a arte contemporânea a uma visibilidade mediática. Transformou a cena institucional, trouxe novos públicos ao museu, criou serviços.

Até ali os museus eram antes de tudo um conservatório, o lugar da História da Arte, responsável pelo acervo material e simbólico da nação, representando o seu mais alto grau de riqueza, poder, desenvolvimento e civilização. Foram designados para resgatar do tempo acelerado do progresso, aquilo que teria sido destruído ou sacrificado em nome do constantemente novo. Ao final dos anos 1970, entretanto, esse museu teve que se adaptar à nova realidade imposta pela crescente consciência da importância do tempo presente, da vida cotidiana, do lazer, do meio ambiente e da cultura. Ao lado disto, as mudanças na orientação do debate crítico e acadêmico, propondo revisões da história da arte, das interpretações canônicas, criando narrativas alternativas com novas seleções e ordenações dos acervos nos museus abertos à interdisciplinaridade, propiciaram o aparecimento de outros métodos de apresentação da produção artística, de novos arcabouços críticos e estruturas conceituais, que transformaram e expandiram o papel das exposições e dos acervos artísticos.

Hoje o público parece buscar os signos que indicam o mais novo, o mais recente, as manifestações de mundos pessoais e originais, sensações e interatividade. Em uma sociedade modelada pela media, as pessoas desejam consumir, ter grandes eventos. A arte é também parte da indústria do entretenimento, e na cultura do espetáculo, o museu, a exposição, a bienal, são produtos respeitáveis. Divertimo-nos acreditando que estamos nos instruindo!

A arte já não é mais um tema em si mesmo. Foi transformada num comentário ou espelho de temas contemporâneos como questões de minorias, memórias traumáticas ou conflitos sociais. Os museus mesmos passaram a encomendar trabalhos sob temas diversos. Desse modo, as exposições temáticas colocaram em evidência não mais a propriedade e a pertinência do museu sob a luz da história, mas de sua utilidade e função social, responsável pelo grau de consciência dessa sociedade sobre si mesma. 
Assim, a passagem da contemplação estética para a assimilação dos conteúdos da arte, criou novas demandas sociais e programáticas para o museu, ampliando suas funções.Agora deve ser didático e educativo num sentido amplo, acessível, engajar comunidades e ser popular, ser político e socialmente proativo e, sobretudo, atender aos patronos e patrocinadores que passaram a viabilizá-lo economicamente. Hoje, o circuito ou o sistema das artes visuais constitui um potente setor econômico, com um sofisticado contingente de profissionais e técnicos, mantidos graças aos recursos públicos vindos de legislações fiscais, que estimulam a filantropia (modelo protestante) e o marketing das corporações (modelo brasileiro). Daí que os confrontos no território do museu não se dão mais em torno da produção de experiência e conhecimento, e sim no alcance de metas e indicadores, de controle financeiro e fiscal, na otimização dos investimentos e redução de custos. Propõe um modo de produção capitalista, empresarial, para o trabalho experimental de pesquisa, reflexão, educação. De preferência com técnicos e profissionais terceirizados e sem considerar a iniqüidade entre os valores da remuneração e dos objetos pelos quais são responsáveis e asseguram a legitimidade. Números e porcentagens são os principais índices de resultados, aferidos anualmente, analisados, comparados, avaliados. Refletem e influem na determinação das políticas, estratégias, causando eventuais desvios das organizações que trabalham o olhar e a percepção visual. Parece não haver possibilidade ou interesse por critérios qualitativos.

Mas a questão é, ainda que sob permanente escrutínio, estão os museus formando um público mais preparado, uma população mais educada visualmente, cidadãos mais responsáveis, comprometidos com o seu tempo e lugar? Aparentemente, não. Este consumo cultural, organizado com a maior eficácia, não favorece a democratização da arte tantas vezes pretextada, mas, pior, promove antes a total des-responsabilização do público. A esse último não se prescreve apenas o que deve ver, mas principalmente lhe é inculcado, graças a um eficiente arsenal didático, como ele deve olhar o trabalho de arte e o que deve tirar disto. Todos se adaptam às condições de produção em vigor. $O$ patrocinador precisa do museu para inserção social da sua imagem ou marca; o museu precisa do público para sua legitimidade financeira e ideológica; o público precisa do museu como autoridade delegada do saber e da cultura. Nesse sistema os museus correm o risco terrível de serem guiados - se é que já não estão - pelas linhas do mercado, que tende a promover as qualidades da inteligência formal, em detrimento da experiência individual, da imaginação, da subjetividade, que a arte faz aflorar em cada sujeito. Pior, se tornaram uma experiência reiterativa.A febre de selfies é o sintoma disto: as pessoas vão conferir e registrar no museu aquilo que já viram na rede.

O desenvolvimento histórico dos museus sempre foi acompanhado pela crítica a eles, mas com uma variedade de argumentos. Nunca falamos de um mesmo museu se consideramos as diversas gerações que já passaram por ele. No entanto, com a transformação dos museus em polos da indústria do turismo, seus serviços tornaram-se mais importantes que os objetos nele, o acontecimento mais importante que a expertise. $O$ patrimônio cultural tornou-se o tema da indústria cultural, assim como a indústria do patrimônio cultural tornou-se o novo modo de produção cultural. Estaria nesse consumo do museu e de seus serviços o futuro da instituição? Até que ponto podemos acreditar em alguma efetividade cultural, algo transformador da experiência de conhecimento e produção de saber dessa nova economia, que movimenta os museus já existentes e cria novos, replicando-os? 
Não acredito que o futuro do museu esteja em uma nova forma de turismo, mas sim em uma nova definição de conteúdos, que privilegie um espaço para a contemplação e o conhecimento, visando formar um público crítico, diferenciado da massa ávida por sensações. Algo que ele sempre fez, bem ou mal. Nada de errado com o fato de termos construído catedrais para as artes, lugares de rituais da cultura, mas que elas sejam um lugar de silêncio e reflexão. Mais: que sejam espaços diferenciados do ruidoso mundo do espetáculo da cultura, do fluxo incessante das redes de informações, da retórica do capital corporativo e da filantropia das elites. O que temos a oferecer é um produto de altíssima qualidade, e nosso objetivo deve ser sempre o de aprimorar o consumidor, espiritual e intelectualmente. A politização do museu pela incorporação de produções avançadas, com temas e agendas sociais e políticas, não parecem ter desencadeado movimentos e ações para fora dos muros do museu. No entanto, o que está lá dentro tem sempre algo de simbólico e, por certo, também algo de catártico, mitigando, desta forma, o desconforto das consciências e a passividade pequena burguesa inerente as origens da instituição museal.

Termina que é melhor tomar seriamente o papel do museu de arte como um lugar para a arte. Somente na coexistência, no compartilhar do espaço institucional e simbólico com a arte do passado, é que se poderá levar adiante o sentido da arte. $\bigcirc$ museu não pode ser legitimado apenas pela incorporação das práticas artísticas contemporâneas, pelas demandas do circuito em que se inscreve, pela economia que põe em movimento. A arte tem que apontar para a sua própria genealogia, de modo a materializar qualquer sentido que ela tenha. Uma das tarefas mais nobres do museu é exatamente a de garantir a presença da arte, assegurar a visibilidade das obras que já foram feitas.

No quadro desta economia de modelos e procedimentos, o debate sobre a digitalização dos e nos museus parece jogar um papel importante, para além da acessibilidade e democratização, assim como a globalização joga na transformação de organizações aos padrões e programas de uma instituição globalizada.

Assumindo que o mundo todo pode ser digitalizado, o museu estaria traindo a sua identidade e natureza ao oferecer seus serviços e programas nessas tecnologias, em lugar de apenas usá-las com propósitos práticos. As suas possibilidades de difusão, propagação parecem ser infinitas e sempre renovadas. Mas, até aqui, ainda se aplica a crítica que se fez ao Museu Imaginário de André Malraux, quanto ao seu caráter artificial e redutor. Em seu famoso texto, ele propõe um museu sem muros, um museu em nossas cabeças, no qual a demanda de um museu real é substituída pela ideia de um museu virtual. Pensava não apenas num museu sem limites, mas numa arte sem limites; um museu com a arte do mundo todo, uma espécie de anti-Louvre, um território sem categorias. Seu modelo propunha não apenas uma mudança do espaço real para o virtual, imaginário, mas também a troca de originais por reproduções fotográficas dos objetos artísticos, criando uma coleção completa de arte por meio de fotografias. Desse modo, o autor propunha um museu global, com trabalhos de todas as partes, porém, segundo a perspectiva da angular de Malraux. Isto é, qualquer trabalho que pudesse ser fotografado poderia ser admitido no Museu Imaginário. Como observou Douglas Crimp (1993), a fotografia não apenas assegurava a admissão de vários objetos, mas era também um instrumento de organização desse museu: ela reduz a vasta heterogeneidade da cultura visual, da experiência do lugar onde ela está ou ocorre, por uma similitude perfeita. O Google Art faz a mesma coisa: propõe a homogeneidade da experiência subjetiva, o apagamento da especialização profissional e da produção de expertise. 
Por sua vez o mundo globalizado oferece a oportunidade única de formarmos uma nova concepção de nós mesmos por meio de experiências de diferenças e alteridades, uma condição necessária, uma oportunidade propícia, para a instalação de um diálogo, de uma troca com outras culturas e práticas criativas. Esse processo tem representado uma abertura geográfica que produziu mais que um alargamento do nosso campo de visão, mais que um simples deslocamento dos polos de interesse: pôs em questão aquilo que estava estabelecido como as fronteiras do mundo da arte, a saber, as fronteiras do mundo ocidental desenvolvido sob a hegemonia da Europa e dos Estados Unidos.

Entretanto, devemos lembrar e entender que mesmo a noção de ocidental implica num caráter local, a despeito dos esforços do modernismo em propor e implementar um projeto universalizante. Homens de negócios e ideólogos podem argumentar quanto ao fato de caminharmos para uma aldeia global, mas o museu, talvez, deve ser deixado fora disso, sozinho como uma igreja paroquial. Qual a vantagem de um museu globalizado, se isto significar a adoção de modelos e procedimentos a partir de organizações que se reproduzem umas às outras, apresentando as mesmas narrativas? Não são, portanto, os objetos, mas as atividades de um museu que podem definir o seu futuro. Não se trata apenas de produzir exposições cada vez mais atraentes, espetaculares, para que com isso se aumente o número de visitantes. Mais importante que isso é que precisamos determinar se queremos ampliar ou mudar a noção de museu e exposição, ou se podemos pensar e propor noções enriquecidas deles e que nunca foram tentadas anteriormente. Assim o museu local permanece como o incorporador das tradições e culturas locais; não como museu de folclore e tradições populares, mas como o espaço privilegiado do debate entre local e global.

De todo modo, é preciso cuidado com o espetáculo das exposições porque, antes de tudo, ele visa um público amplo e indiscriminado, uma entidade abstrata no centro de políticas oficiais para a cultura e patrocinadores. É possível, portanto, oferecer algum papel alternativo para o público? Qual seria ele? Minha colocação aqui é mais para trazer uma provocação, lançando uma pergunta que talvez não tenha resposta. $O$ importante é continuar fazendo-a. Assim como todas aquelas que já sabemos relativas a todos os museus e com as quais vimos nos debatendo por anos desde a sua criação: a coleção, os serviços educativos, as mostras temporárias, as publicações, os recursos financeiros, etc.

Em sua curta história o museu já mudou bastante e continua mudando, sem que esse processo tenha destruído ou fragilizado a instituição. $O$ museu não é diferente da sociedade que o financia e o põe em movimento. Ele é, desde sempre, um meio de conhecimento e que não existe sem ou em oposição ao seu uso. Entretanto, quando parece que dizer que ele já não serve aos termos gerais que o definem, "para a arte", ele continua sendo percebido e legítimo como antípoda aos meios de comunicação de massa. Pelo menos é assim que o vendem: ele nos convida a experiências de coisas e lugares, nos oferece a possibilidade de constituição de memórias e lembranças. Mas, ao mesmo tempo, ele também nos convida a intervir nas tecnologias correntes e não simplesmente interagir com elas. $O$ museu parece ainda passível de outros papéis, diferentes daqueles que teve até agora. Se aceitarmos essas premissas isto quer dizer que podemos continuar desafiando e buscando novos papéis para o museu e para o que nós, profissionais deste campo, podemos fazer com ele. $\bigcirc$ que não podemos é aceitar e preferir viver em uma realidade criada, os museus como indústria cultural, em lugar de organizar uma nova realidade negociada. 


\section{Referências}

CRIMP, Douglas. On the museums' ruins. Cambridge, Mass.: MIT Press, 1993.

Recebido em janeiro de 2017.Aprovado em abril de 2017. 